\title{
Time-predictable model application in probabilistic seismic hazard analysis of faults in Taiwan
}

\author{
Yu-Wen Chang ${ }^{1,2}$, Chin-Hsiung Loh ${ }^{2, *}$, and Wen-Yu Jean ${ }^{1}$ \\ ${ }^{1}$ National Center for Research on Earthquake Engineering, National Applied Research Laboratories, Taipei City, Taiwan \\ ${ }^{2}$ Department of Civil Engineering, National Taiwan University, Taipei City, Taiwan
}

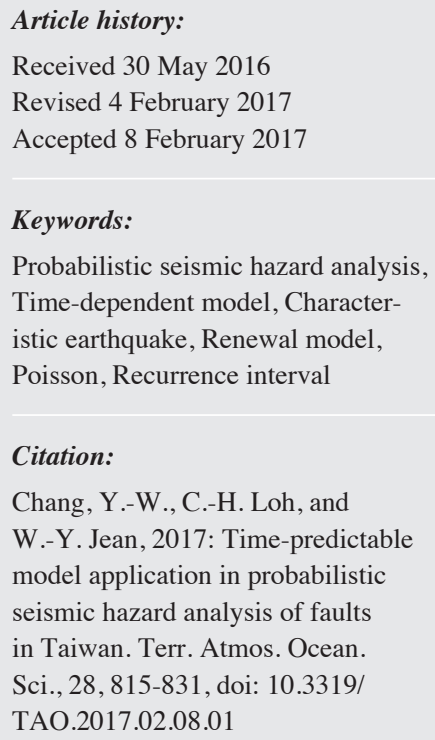

\begin{abstract}
Given the probability distribution function relating to the recurrence interval and the occurrence time of the previous occurrence of a fault, a time-dependent model of a particular fault for seismic hazard assessment was developed that takes into account the active fault rupture cyclic characteristics during a particular lifetime up to the present time. The Gutenberg and Richter (1944) exponential frequency-magnitude relation uses to describe the earthquake recurrence rate for a regional source. It is a reference for developing a composite procedure modelled the occurrence rate for the large earthquake of a fault when the activity information is shortage. The time-dependent model was used to describe the fault characteristic behavior. The seismic hazards contribution from all sources, including both time-dependent and time-independent models, were then added together to obtain the annual total lifetime hazard curves. The effects of time-dependent and time-independent models of fault [e.g., Brownian passage time (BPT) and Poisson, respectively] in hazard calculations are also discussed. The proposed fault model result shows that the seismic demands of near fault areas are lower than the current hazard estimation where the time-dependent model was used on those faults, particularly, the elapsed time since the last event of the faults (such as the Chelungpu fault) are short.
\end{abstract}

\section{INTRODUCTION}

Probabilistic seismic hazard analysis provides a key element for engineering seismic design. It is concerned with evaluating the various natural effects of earthquakes at specific levels, which may cause safety or design consequences to critical structures at particular sites such as dams, public structures, and nuclear power plants. The methodologies for performing a probabilistic seismic hazard analysis (PSHA), as initially described by Cornell (1968), McGuire (1976), Der Kiureghian and Ang (1977), and others, are well established in engineering practice. The PSHA provides a framework to address the uncertainties associated with the identification and characterization of seismic sources by incorporating multiple seismological parameter interpretations.

For a particular site, the hazard contributions are integrated over all magnitudes and distances for all source zones, according to the calculation of total probability theory. Figure 1 schematically illustrates the constituent models

\footnotetext{
* Corresponding author

E-mail:lohc0220@ccms.ntu.edu.tw
}

of the probabilistic approach to estimate earthquake ground motion hazard. The earthquake magnitude recurrence models are for each source characterization, respectively. Secondly, a ground motion prediction equation is selected, that is, in general an empirical relationship among the ground motion characteristics (such as the style of faulting, magnitude and distance and the local site geology). The third step consists of evaluating the probability of exceedence for a given ground shaking intensity in some period of interest at a specific site. Thus, the annual probability of exceeding the ground motion $Y$ for a given specific ground motion level $y$ is shown below:

$$
\lambda(y)=\sum_{i=1}^{n} v_{i}\left\{\int_{m} \int_{r} P[Y>y \mid m, r] f_{r}(r \mid m) f_{m}(m) d r d m\right\}
$$

where $v_{i}$ is the annual rate of the $i$ source zone for $m \geq m_{0}$ earthquakes, $m$ is the earthquake magnitude, $r$ is the distance from the site to source, $P[-\mathrm{I}-]$ is the conditional probability, 
and $f_{m}(m), f_{r}(r \mid m)$ are the probability density functions for earthquake magnitude and distance, respectively.

Two major sources of probabilistic uncertainties are raised to incorporate both seismicity and geologic information in PSHA (McGuire 2004): (1) Aleatory uncertainties that are inherent in a random phenomenon and cannot be reduced by acquiring additional data or information; and (2) Epistemic uncertainty is the scientific uncertainty in the model or process. It is due to limited data and knowledge. There is no doubt that these uncertainties will lead to variations in even the best seismic hazard estimation. Obviously, the analysis must effectively account for the spatial and temporal randomness of earthquake occurrences to improve confidence in PSHA. Up-to-date knowledge of the source data along with accurate models can provide valuable information in reducing such uncertainties and in facilitating a correct understanding of PSHA.

Most of the developments in PSHA have been primarily concerned with introducing different probabilistic models to describe randomness, such as earthquake magnitude, occurrence time and occurrence rate, in order to achieve more realistic descriptions for a specific site. One of the main steps in PSHA involves evaluating the recurrence rate for a given earthquake magnitude from the seismic source (step 1 in Fig. 1). The earthquake occurrence model, i.e., the specification of where and how frequently earthquakes are likely to occur, is a main component. The GutenbergRichter (Gutenberg and Richter 1944) relation is a basic formula for calculating the recurrence rate in a zone according to the earthquake activity characteristics (McGuire 1976, 1995; Der Kiureghian and Ang 1977). Due to physical source fault constraints (earthquake magnitude is related to the area of the seismic rupture), earthquake magnitude must have an upper bound in a region. The corresponding probability density of the Gutenberg-Richter relation using the earthquake magnitude limit is expressed below:

$$
f_{m}(m)=\frac{\beta \cdot e^{-\beta\left(m-M_{\min }\right)}}{1-e^{-\beta\left(M_{\max }-M_{\min }\right)}}
$$

where $\beta=b \ln 10$ ( $b$ is the $b$-value of the Gutenberg-Richter relation), and $M_{\max }, M_{\min }$ are the maximum and minimum magnitudes of the region of interest, respectively. Equation (2) is also called the truncated exponential model. However, the earthquake occurrences, as defined by the Poisson process, are characterized by an exponential distribution of the earthquake recurrence intervals, $\lambda$ [estimated by the Eq. (1)] The probability density function and cumulative distribution function are shown in Fig. 2. In addition, the procedure utilized in PSHA is based on the memory-less assumptions of the Poisson processes in which time, size and location of preceding events are independent.

In reality, there is increasing evidence that using the characteristic earthquake model for large earthquake, generated from an individual fault, is more appropriate than using the Gutenberg-Richter relation (Wesnousky and Scholz 1983; Schwartz and Coppersmith 1984; Youngs and Coppersmith 1985; Hong and Guo 1995; Parsons 2005, 2006; Parsons and Geist 2009). Figure 3 shows that the characteristic earthquake model indicates a non-linear earthquake frequency-magnitude relation dominated by the characteristic events (Schwartz and Coppersmith 1984; Youngs and Coppersmith 1985). In the frequency-magnitude relationship, a very low $b$-value is required in the moderate-magnitude range to reconcile the data throughout the range of magnitudes (Wesnousky 1994). Based on the energy accumulation concept (consistent slip rate), the behavior of large earthquakes related to the individual fault source follows an inherent time model. The characteristic earthquake model is based on the observation that during repeated rupture episodes occurring on the individual fault (or fault system), some characteristics remain approximately constant over a large timescale; the rupture characterization of the earthquake occurrence behavior does not match the assumption using the Poisson process. It is important to properly consider the variability in recurrence rates caused by multiplesegment ruptures that change from event to event due to fault interaction. Furthermore, the simple elastic rebound theory of elastic strain accumulation and relaxation suggests there is some renewal process involved in earthquake recurrence on individual faults.

The frequency of large earthquake occurrence forms the basis for seismic hazard assessments, while the concept of a stress-driven earthquake renewal inspires time-dependent earthquake probability calculations. In fact, in recent years, the time dependent occurrence model has been applied increasingly as part of PSHA (e.g., Ogata 1999; Ellsworth et al. 1999; Cramer et al. 2000; González et al. 2006; Jean et al. 2006; Chang et al. 2007; Akinci et al. 2010; Garcia-Aristizabal et al. 2012; Mosca et al. 2012). The timedependent hazard analysis in the San Francisco Bay region using the probability models for the major Bay Area faults was considered by the U.S. Geological Survey's (USGS) Working Group on the California Earthquake Probabilities study (WGCEP 2003). It performed time-dependent probability calculations for the next 30 years using historic earthquake data from the segmentations of active faults, such as the San Andreas.

Paleoseismic trench excavations have also provided information, including fault geometry, displacement, focal mechanism, and fault slip rate. It provided data that prove recurrence intervals to be consistent with an assumed probability function. Based on the fault displacement of the Chelungpu fault (reported by Chen et al. 2000, 2004, 2007) and the Longitudinal Valley (reported by Yen et al. 2008) fault in Taiwan, the magnitude of a paleoearthquake can be estimated using the relationship of average displacement to 


\section{Probabilistic Seismic Hazard Analysis}

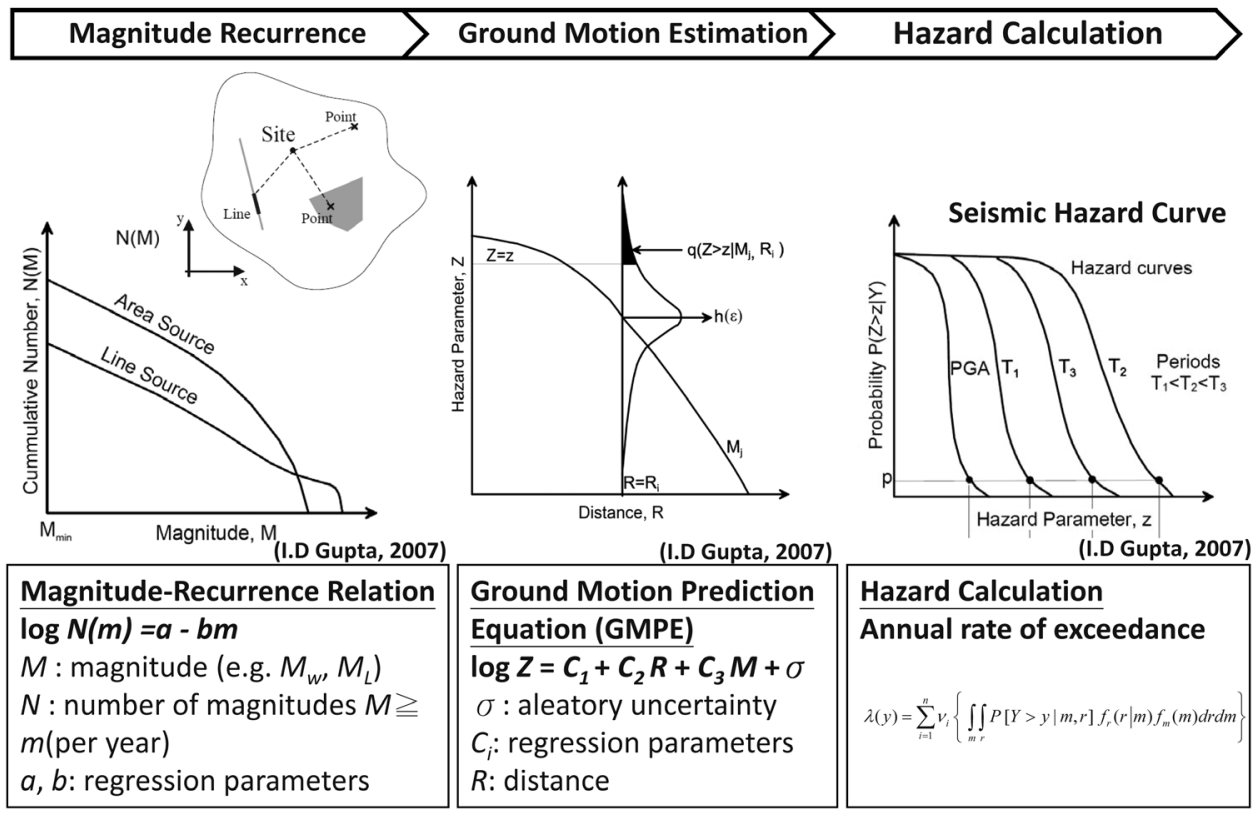

Fig. 1. Schematic illustration of the basic three steps in probabilistic seismic hazard analysis.

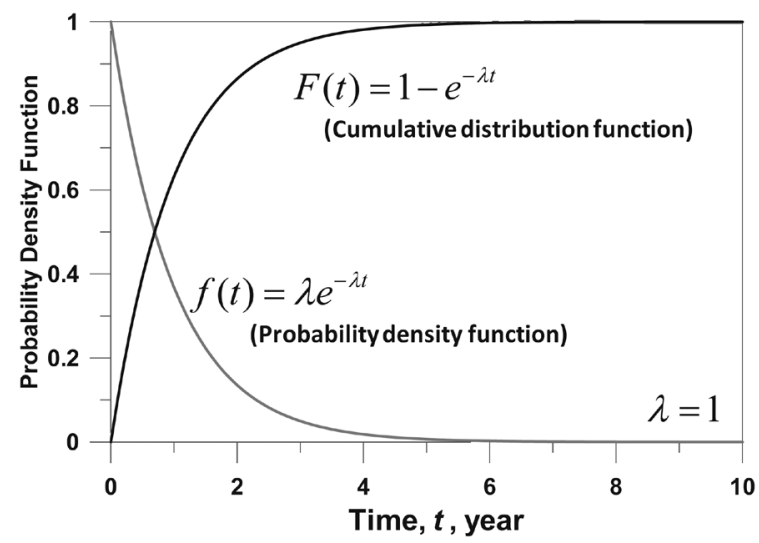

Fig. 2. The probability density function (pdf) and cumulative distribution function (PDF) of Poisson process.
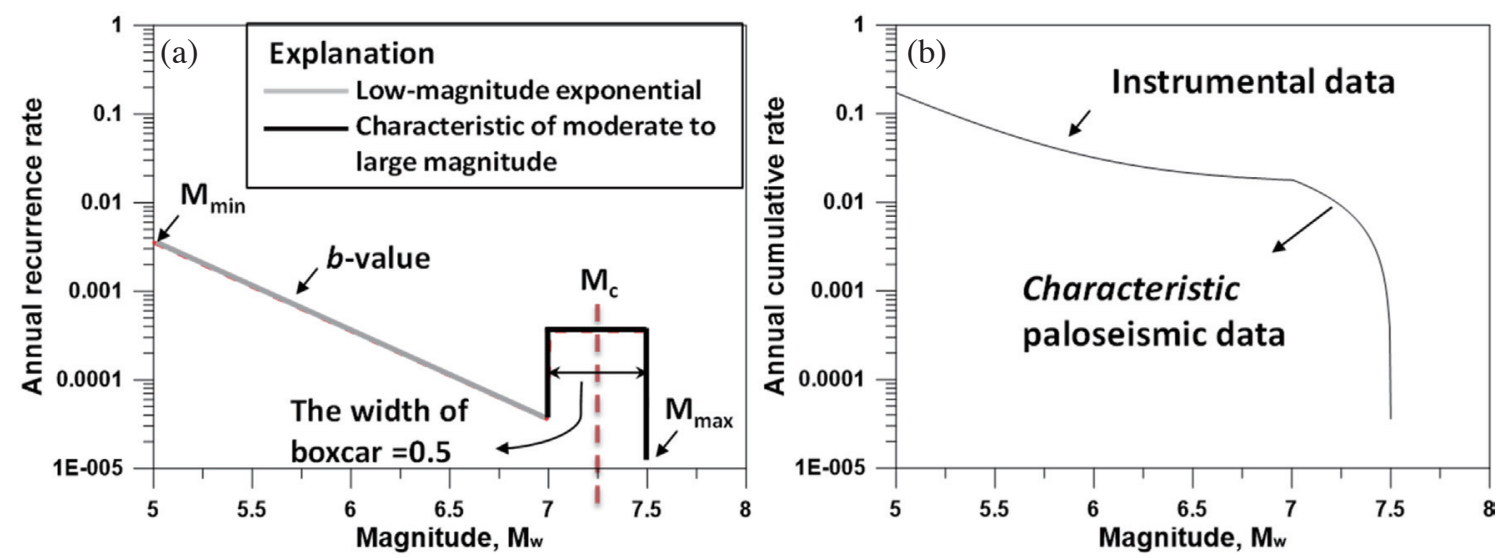

Fig. 3. The Characteristic Earthquake Model from Youngs and Coppersmith (1985). On the (a) is the schematic illustration of the characteristic earthquake model; the (b) is the cumulative probability density magnitude of the model. (Color online only) 
the moment magnitude by Wells and Coppersmith (1994). As shown in Fig. 4, due to the cumulative seismic moment converted from moment magnitude [the moment magnitude scale referring from Hanks and Kanamori (1979)], the earthquake recurrence behavior of characteristic events has been proven to follow the time-dependent process. Using the Poisson time-independent process calculates the recurrence rate of such an individual rupture for fault may overestimate or underestimate its hazard contribution. This implies that the probability for an earthquake occurrence for a given year does not depend on the elapsed time since the last event.

Although time-independent earthquake occurrence behavior characterization requires only an assessment of the average recurrence time for a given magnitude, this study considers the elapsed time since the last earthquake in timedependent earthquake models for major faults in Taiwan. The paleoseismic data of the Chelungpu and Longitudinal Valley faults helps to estimate the conditional probability corresponding to a renewal model with the coefficient of variation (COV). In addition, COV is a key parameter in time-varying probability estimates, particularly the standard deviation of recurrence intervals for a given fault system between large events. However, the conditional probability in the next subsequent time depends on the ratio between the elapsed time and the recurrence interval of a fault $\left(T_{e} / T_{r}\right.$ ratio). In addition to a small $T_{e} / T_{r}$ ratio of the Chelungpu fault, a large $T_{e} / T_{r}$ ratio of the Meishan fault is discussed in this paper.

\section{SEISMOTECTONIC FRAME AND ACTIVE FAULTS IN TAIWAN}

Taiwan is located in the convergent plate boundary of the Eurasian plate colliding with the Philippine Sea plate at a rate of about $70-80 \mathrm{~mm} \mathrm{yr}^{-1}$ (Yu et al. 1997). This area is one of the most seismically active regions in the world. This tectonic environment produces a complex distribution of active faults, causing high seismicity within and around Taiwan. Statistics indicate that more than 7,780 people have died due to earthquakes in the last century (Cheng et al. 1999). Devastating earthquakes occur in Taiwan mostly from ground ruptures or the reactivation of faults, such as the 1999 Chichi Taiwan Earthquake with $\mathbf{M}_{w}=7.6$ in Central Taiwan due to a surface rupture longer than $105 \mathrm{~km}$ along the Chelungpu fault.

Characteristic earthquake behavior is suggested mainly by geological observations and/or trenching surveys. Unfortunately, basic information on the paleoseismicity of the active faults in Taiwan are virtually lacking from geological mapping. Therefore, after the 1999 Chichi Taiwan Earthquake, the data collected from trenching studies were used to characterize the slip rate and the amount of displacement per event that characterize the Holocene behavior of active faults. The trenching studies allow estimating the age of paleoseismic events and the recurrence intervals for seismic hazard assessments.

\subsection{The Paleoseismological Investigation in Taiwan}

Four fundamental elements need to be considered in the seismic source characterization of active faults: (1) the identification, location and geometry of significant earthquake sources; (2) the maximum size of the earthquakes associated with a fault; (3) the renewal rate at which fault rupture occurred; and (4) the occurrence time of the last event. The paleoseismological investigation goals for individual faults are to provide basic information on the interval between

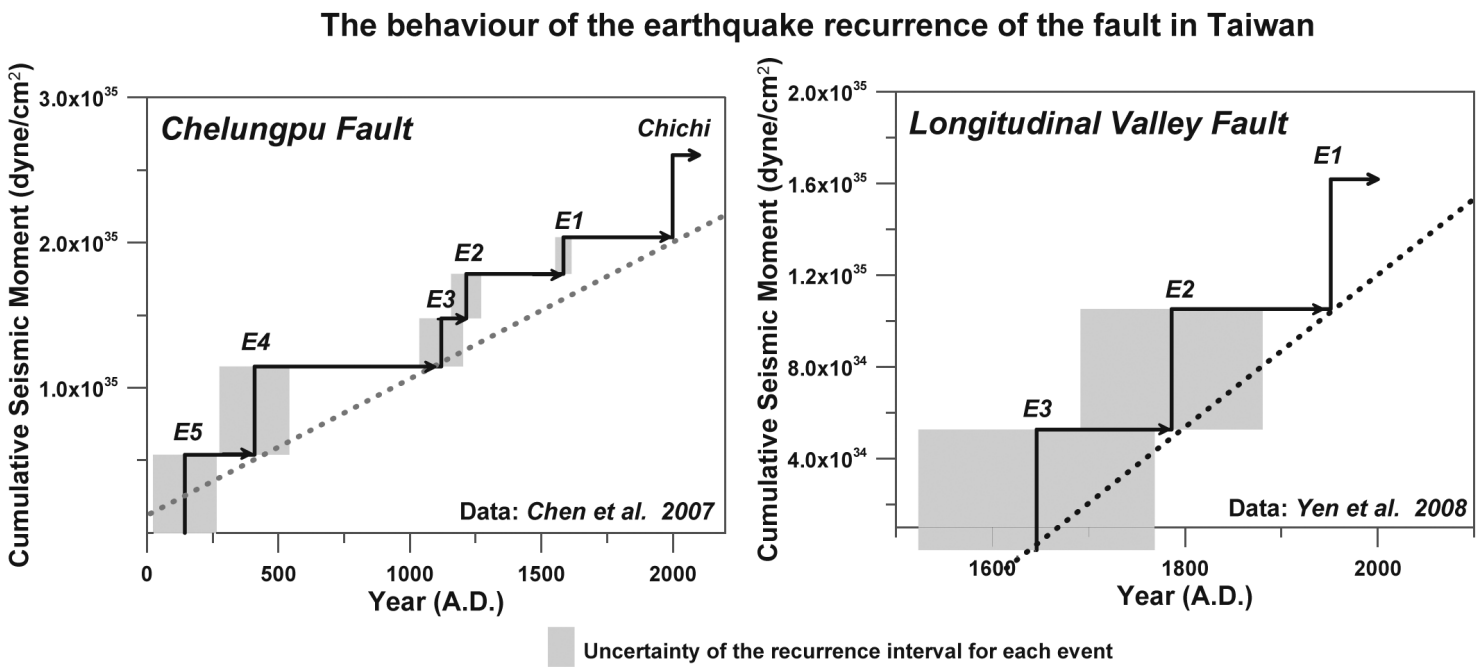

Fig. 4. The behaviour of the earthquake recurrence in the Chelungpu fault (left) and the Longitudinal Valley fault (right) in Taiwan follows the time-predictable model based on a consistent slip rate level at which failure occurs. In this figure, the moment magnitude scale referring from Hanks and Kanamori (1979): $M=2 / 3 \cdot \log M_{0}-10.7$. 
earthquake-induced surface faulting, the displacement during each event, slip rate, and fault segmentation. This information forms the basis for estimating the magnitude of paleoearthquakes and the earthquake recurrence renewal model. In fact, paleoseismic evidence in several different tectonic environments (e.g., Japan, Turkey, California etc.) supports the idea that the reoccurring ruptures on a fault can be described by a time-predictable model. The conclusion from paleoseismological investigations in Taiwan indicated that the behavior of rupture episodes at active faults adhere to a time-predictable model, based on a consistent slip rate level at which the earthquake occurs, such as the Chelungpu fault (Chen et al. 2004, 2007) or the Longitudinal Valley fault (Yen et al. 2008) etc. (as shown in Fig. 4). The recurrence times are based on the paleoseismic determinations of the dates of old large earthquakes, which may contain measurement uncertainties.

The 1999 Chichi, Taiwan, Earthquake caused a clear surface rupture over $105 \mathrm{~km}$ in length along the Chelungpu fault. This is a good seismic event for paleoseismological study. Seven trenches were excavated along this fault to investigate the history of large earthquake events. The excavations along the Chelungpu fault characterized six large earthquake events in A.D. 1999, A.D. 1699 - 1569, A.D. 1319 - 1209, A.D. 1289 - 1049, A.D. 619 - 299, and A.D. 289 - 69 during the past 2 millennia (Chen et al. 2007; http:// cgsweb.moeacgs.gov.tw/). The average slip rate of the Chelungpu fault is $6.4 \mathrm{~mm} \mathrm{yr}^{-1}$. As shown in Fig. 5a, the mean recurrence interval for the six characteristic earthquakes is about 365 years and the variance is small with a COV of 0.356 . This small COV value is similar to that in some other research results. When COV has low value, the earthquake occurred with a very periodic process. Past studies of the investigative data from several major fault systems found that the range of $\mathrm{COV}$ for repeat times for large events on a fault or the transform and subduction plate boundaries is within 0.2 - 0.4 (e.g., Nishenko and Buland 1987; Sykes and Menke 2006), especially the Parkfield section of the San Andreas fault with COV $=0.37$ (Sykes and Menke 2006). Cornell and Winterstein (1988) proposed the typical COV values in practice range from $0.4-0.6$. These COV values determined using geological investigation are smaller than the Jackson et al. (1995), which assumed renewal processes with larger COV of $0.5 \pm 0.2$ for the most active fault segments in the San Francisco Bay area.

The Longitudinal Valley fault, which consists of many segments, is currently the major seismogenic fault in East Taiwan. The Longitudinal Valley fault is also the most important plate boundary fault between the Philippine Sea Plate and the Eurasian Plate in Taiwan. Three sites were investigated along the Longitudinal Valley fault by Yen et al. (2008), who identified three surface-rupturing earthquakes within the past 390 years, including the 1951 earthquake. This data yielded a relatively short mean recurrence interval of approximately 150 years, as shown in Fig. 5b. Although the uncertainty of the recurrence interval of the paleoearthquake is indeterminate in the fault, based on the fault dipping angle and the vertical uplift rate, the more accurate fault slip rate can be calculated using trigonometry. The Longitudinal Valley fault slip rate was estimated between 17.0 - $24.4 \mathrm{~mm} \mathrm{yr}^{-1}$ (Yen et al. 2008).

Not all pale-seismological studies can provide enough information to estimate the recurrence intervals and its uncertainty. Although the Longitudinal Valley fault was identified as presenting a few paleoearthquakes during a specific period, the uncertainty of the recurrence intervals for these paleoearthquakes is indeterminate in the fault. The information shortage about the recurrence interval uncertainty exists (a) Chelungpu Fault

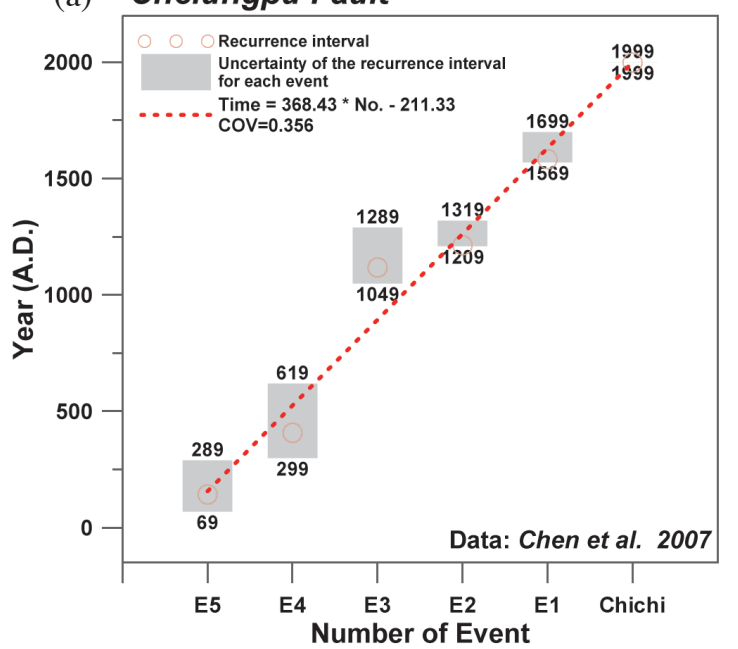

(b) Longitudinal Valley Fault

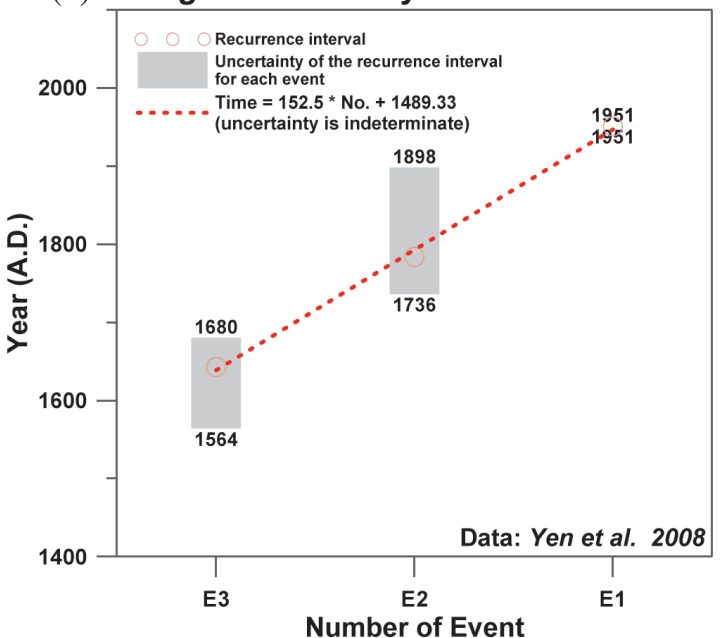

Fig. 5. The paleoseismological fault data and its mean occurrence interval. On the (a) is the recurrence interval of the Chelungpu fault was estimated about 365 years, and the (b) is the recurrence interval of the Longitudinal Valley fault was estimated about 150 years. (Color online only) 
in most faults in Taiwan, such as the Meishan fault at which only two historical earthquakes occurred, i.e., in 1792 and 1906. It is difficult to estimate appropriate COV for the fault renewal model. However, alternative COV for the Longitudinal Valley and the Meishan faults for the time-dependent model should be referred from other the major faults that have periodic behaviour and for which sufficient information on previous earthquakes is available. In this case, according to the typical COV values in practice range from 0.4 - 0.6 (Cornell and Winterstein 1988; Jackson et al. 1995), a conservative $\mathrm{COV}=0.5$ was used in the Longitudinal Valley and the Meishan faults, respectively. The characteristic earthquake model has significant implications for seismic hazard assessments associated with a particular fault. Each fault has an extensive geological and seismological dataset that defines the behavior of certain faults (e.g., Wasatch and San Andreas Fault system; the Chelungpu fault) (Schwartz and Coppersmith 1984). For well-instrumented active faults, the recorded information may possibly be used to estimate the recurrence rates for large earthquake events on an individual fault directly from the paleoearthquake investigation. The paleoseismological studies have proven extremely important in quantifying the fault-specific earthquake recurrence and its historical magnitude.

\section{TIME-PREDICTED EARTHQUAKE MODEL}

Implementation of a selected earthquake recurrence distribution model in earthquake hazard calculation is critical. However, the Gutenberg-Richter relation works well for large regions in general, but in most cases, the relationship underestimates the number of earthquakes with moderate to large magnitudes, such as the characteristic earthquakes of a fault (Schwartz and Coppersmith 1984; Wesnousky 1994). In particular, implied by the elastic-rebound theory, the renewal models are used to quantify the earthquake probabilities. On the contrary, the time-dependent model is typically applied to larger-magnitude earthquakes that are modeled as characteristic events on a single fault, with magnitudes close to a central value $M_{c}$ (Fig. 3). Without loss of generality, the areal seismic source occurrence is modeled using a time-independent model, e.g., the Gutenberg-Richter relation. In contrast, the probability distribution of the occurrence rate for an individual fault is more applicable using the paleoseismological event renewal process and geological observations.

\subsection{Renewal Models}

To represent the earthquake occurrence with respect to time, it is assumed that the occurrence of large earthquakes is periodic. This assumption is taken into consideration along with the energy accumulation of previous events through an earthquake renewal model. Renewal models were applied to different distributions which allow the probability of fault occurrence to increase with respect to the elapsed time $\left(T_{e}\right)$ since the occurrence of the last event with the subsequent $T_{p}$-year. The typical distributions for describing earthquake recurrence include the Exponential (Poisson), Log-normal, Weibull, Gamma, or Brownian Passage Time (BPT) (Matthews et al. 2002). The BPT distribution is based on a simple physical earthquake cycle model and has highly desirable statistical properties in describing the earthquake recurrence statistics. This distribution has been widely used in California and Japan (Fujiwara et al. 2005; WGCEP 2007; Field et al. 2015), among other studies (Ellsworth et al. 1999; Matthews et al. 2002; Fujiwara et al. 2009; Akinci et al. 2010; Garcia-Aristizabal et al. 2012). The probability density of the BPT model is given as follows:

$f^{B P T}(t)=\sqrt{\frac{\mu}{2 \pi \alpha^{2} t^{3}}} \cdot \exp \left[-\frac{(t-\mu)^{2}}{2 \mu \alpha^{2} t}\right]$

where $\alpha$ is a dimensionless measure of $\mathrm{COV}$ (also known as the aperiodicity) of the distribution, and $t$ is the time. The other probability distributions can be referred from the statistics textbook. Different probability density functions $[f(t)]$ of renewal model, normalized time ratio for the earthquake recurrence interval $\left(T_{r}\right)$, with $\mathrm{COV}$ equal to 0.5 are illustrated in Fig. 6a.

The hazard function $h(t)$ describes the instantaneous rate of failure at time $t$ given that no event occurred until time $t$. It is defined as

$h(t)=\frac{f(t)}{R(t)}=\frac{f(t)}{1-F(t)}$

where $F(t)$ is the cumulative distribution function for the fault recurrence and the probability density function, $f(t)$, can be any distribution. In other words, an increasing hazard function of time $t$ indicates that an event is likely to occur at a given increment of time, which depends on the memory of the previous event. Figure $6 \mathrm{~b}$ shows the hazard function for the five distributions under discussion. In fact, it indicates that the exponential distribution provides the constant hazard function, which implies that an earthquake occurrence is unrelated to the elapsed time and confirms the stationary nature under the Poisson assumption. The non-zero hazard rate at $t$ $=0$ indicates that there is a possibility for earthquake occurrence immediately following the preceding event. All other models conform to the probability for earthquake occurrence increasing with increasing ratio between the elapsed time and mean recurrence interval. The BPT distribution starts at zero at time $t=0$ in the hazard function and keeps a constant hazard function level after ample elapsed time. This is unlike the Log-normal distribution that will decrease to zero. The hazard function of the Weibull distribution starts at zero, but 
the function increases indefinitely, while the Gamma distribution also has a finite asymptotic failure rate, but the function increases more smoothly (Matthews et al. 2002; Akinci et al. 2010; Garcia-Aristizabal et al. 2012).

From the report on the paleoearthquakes study on the Chelungpu fault, the intervals in the past 2 ka (kilo-years ago) range from about 700 - 100 years and relate to COV $=0.356$. It is assumed that all five models, representing the probability density function of the earthquake recurrence interval, also using COV $=0.356$, as shown in Fig. 7. The time-axis is normalized by the expected value $T_{r}$. The cumulative probability data points of the paleoearthquakes of the Chelungpu fault are plotted in Fig. 7 for comparison. In addition to $\mathrm{COV}=0.356$, the $\mathrm{COV}=0.5$ and 0.7 are also used in the BPT distribution in the same plot. In the statistical analyses, the QQ-plot displays a quantile-quantile plot of two observed data samples and model values. If the samples do come from the same distribution, the plot will be linear or close to 1:1. Based on the paleoearthquake data from the Chelungpu Fault, the QQ-plots of the five distribution models show that the four renewal models have the best performance for describing the characteristic behavior than the exponential (Poisson) model, as illustrated in Fig. 8. In the plot, the sample data is displayed with the plot symbol ' + ' and the red line is a robust linear fit of the order statistic of the two samples. In the test, the exponential (Poisson) model result indicates that the rupture episode behaviour for specific faults cannot unilaterally be described by a constant occurrence rate. It is a reason that the WGCEP (2003) has considered the weighting for the time-independent and timedependent models to build the hazard map. The data show good agreement with the assumed probability distribution function, which indicates that the uncertainty of the time investigation for the paleoearthquake occurring consists with COV of $0.35-0.5$.

\subsection{Calculation of time-dependent probability in hazard analysis}

Let $f(\xi)$ denote a probability density function of the recurrence interval of the fault rupture that causes the earthquake. The probability of the fault surviving up to time $t$, counted from the last rupture occurrence, can be expressed as

$$
R(t)=1-Q(t)=1-\int_{0}^{t} f(\xi) \cdot d \xi=\int_{t}^{\infty} f(\xi) \cdot d \xi
$$

where $Q(t)$ is the failure distribution function of the fault and the probability density function, $f(\xi)$, can be any probability distribution. If the elapsed time of a time-predictable active fault is given as $T_{e}$, the hazard analysis is trying to estimate the occurrence probability of the fault during the subsequent $T_{p}$-year. For most structures, the earthquake design is estimated based on the structural lifetime. In this case, $T_{p}$ is set as the structural lifetime, and the seismic hazard due to the active fault can be estimated using the engineering reliability theory. Given a condition that the fault has survived during $\left[0, T_{e}\right]$, the probability of causing fault rupture during $\left[T_{e}, T_{e}+T_{p}\right]$ is called the posterior failure probability (or recurrence probability):

$$
\begin{aligned}
& Q_{c}\left(T_{e}+T_{p} \mid T_{e}\right)=\frac{Q_{c}\left[T_{e}+T_{p}, T_{e}\right]}{Q_{c}\left[T_{e}\right]}=\frac{\int_{T_{e}}^{T_{e}+T_{p}} f(\xi) \cdot d \xi}{\int_{T_{e}}^{\infty} f(\xi) \cdot d \xi} \\
& =1-\frac{R\left(T_{e}+T_{p}\right)}{R\left(T_{e}\right)}=1-\exp \left[-\int_{T_{e}}^{T_{e}+T_{p}} h(\xi) \cdot d \xi\right]
\end{aligned}
$$

The rate $Q_{c}\left(T_{e}+T_{p} \mid T_{e}\right)$ represents the conditional probability $\left(P_{c o d}\right)$ in the consequent time period. Substituting the $T_{p}$-year conditional probability $\left(P_{c o d}\right)$ for the Poisson probability per
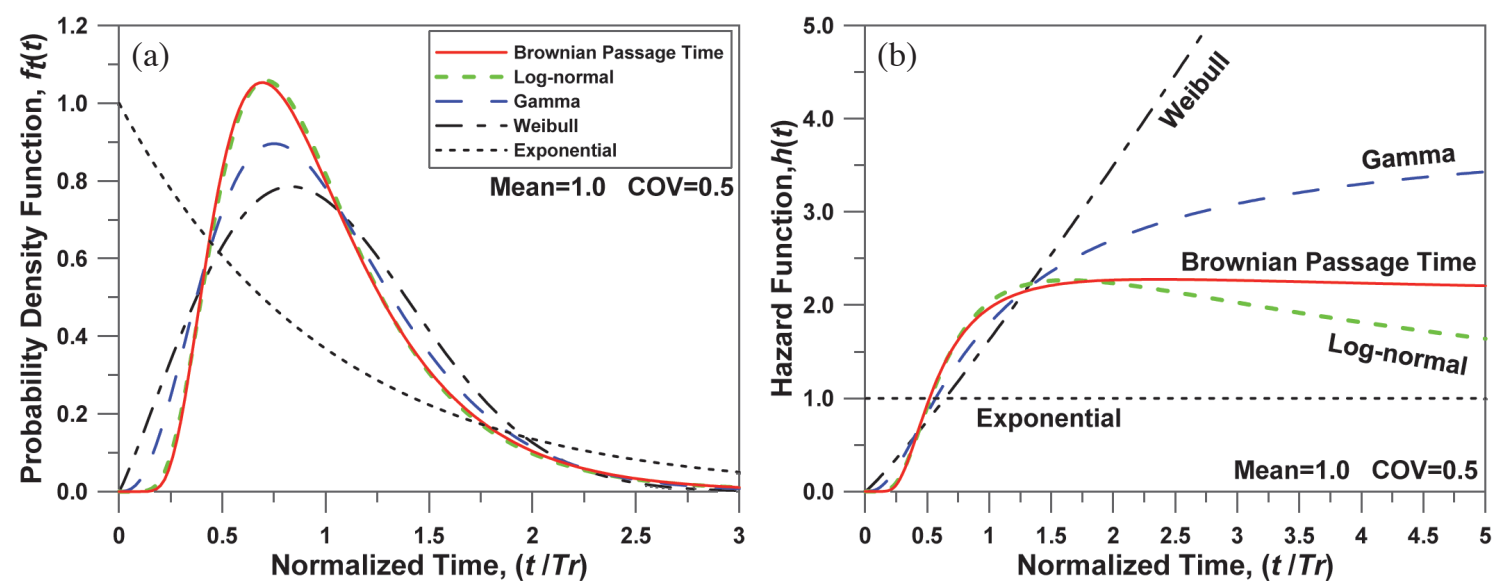

Fig. 6. (a) Probability density distribution and (b) the Hazard function of the Exponential (Poisson) model, Brownian Passage Time model, Lognormal model, Gamma model, and Weibull model. All distributions have mean $=1$ and standard deviation $=0.5$ (except the exponential distribution). (Color online only) 


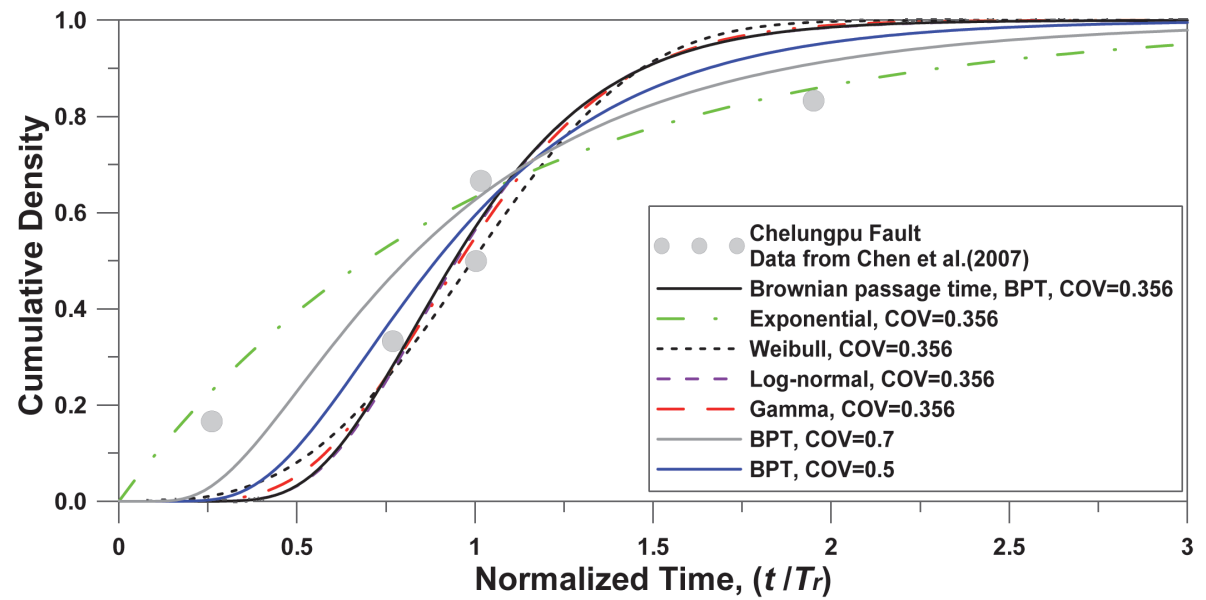

Fig. 7. Comparison of the five distributions and the recurrence-time data from paleoseismological investigation of the Chelungpu fault, including $\mathrm{COV}=0.356$. In addition, the BPT distribution using $\mathrm{COV}=0.5$ and 0.7 are also plotted. (Color online only)
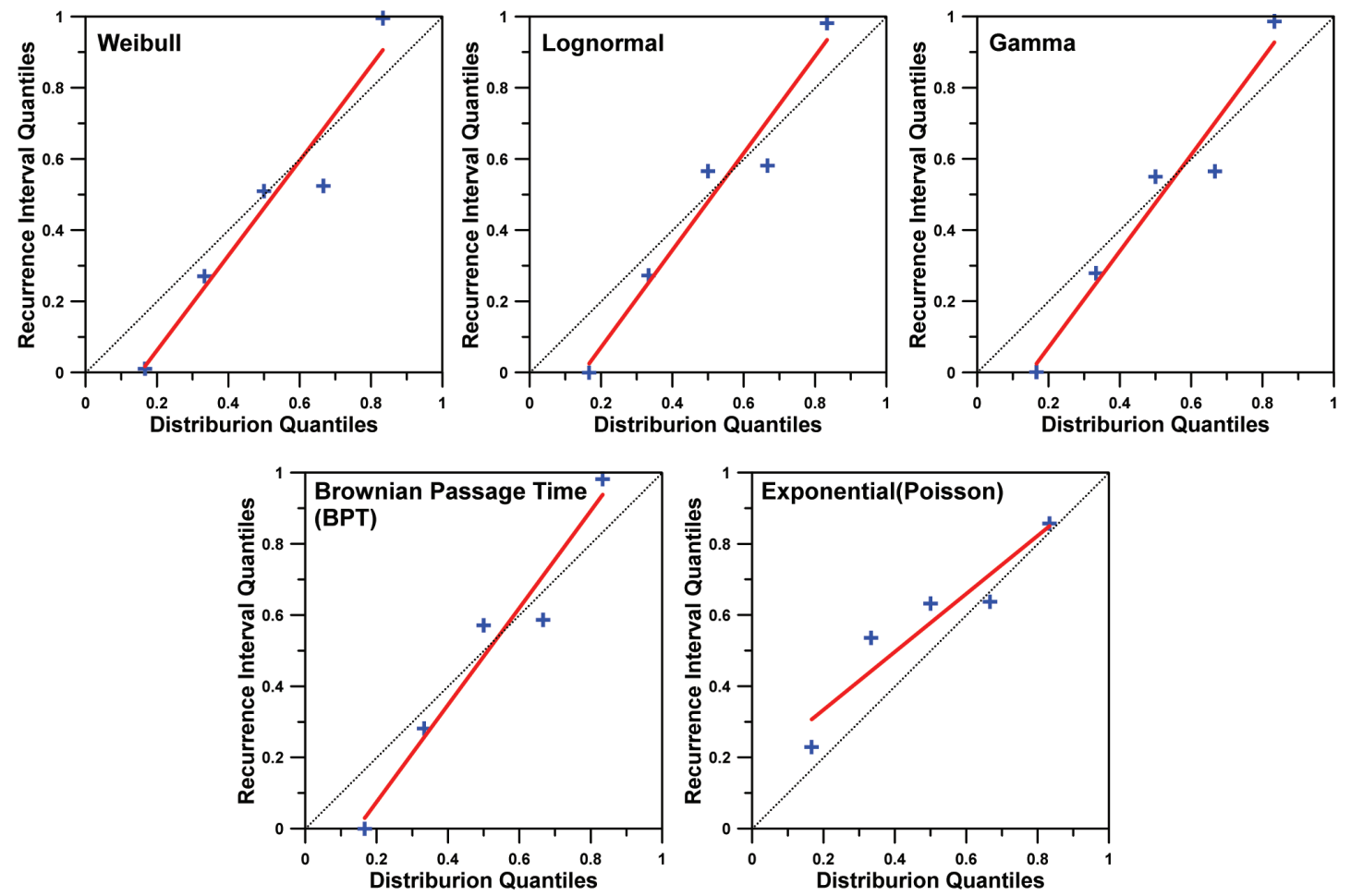

Fig. 8. The QQ-plots of the paleoearthquake data of the Chelungpu fault and the five distribution models. The distribution models include the Weibull model, Log-normal model, Gamma model, Brownian Passage Time model, and Exponential (Poisson) model. Assuming COV = 0.356 of the Chelungpu fault. In the plot, the sample data is displayed with the plot symbol ' + ' and the red line is a robust linear fit of the order statistic of the two samples. In the test, the results shows that the robust linear of renewal models fit more closely to the line of 1:1 than the Poisson model fitting. (Color online only)

year into the Poisson process, an effective Poisson rate $\left(\lambda_{\text {eff }}\right.$, WGCEP 2003) can be solved using:

$\lambda_{\text {eff }}=-\ln \left(1-P_{\text {cond }}\right) / T_{p}$

Thus, an effective $T_{p}$-year rate per year for the active faults was applied in PSHA as a proxy for time dependence.

The Characteristic earthquake of a fault recurrence in PSHA is commonly modelled as the Characteristic Earthquake Model (Youngs and Coppersmith 1985). This model has a uniform distribution for the large earthquakes range and an exponential distribution for the smaller size earthquakes. The uniform distribution is centred on the mean 
characteristic magnitude, $M_{c}$, and has a width of $0.5 \mathrm{mag}$ nitude, as illustrated in Fig. 3a. In the characteristic earthquake model the individual fault slip rate is an important parameter that describes the earthquake recurrence. However, it cannot be easily estimated using geological, paleoseismological and/or geodetic evidence. The individual fault slip rate was developed by Shyu et al. (2016) based on the seismogenic structural data in Taiwan. In addition to the historic earthquakes, the slip rate is a parameter to estimate the fault recurrence interval. The recurrence interval of the study faults was determined from the fault paleoseismological data in this study.

In the fault recurrence interval application, the simplified "characteristic earthquake model" in which the truncated exponential model with low $b_{c}$-value describes the characteristic earthquakes range along a particular fault segment is assumed to have an effective $T_{p}$-year rate per year $\left[\lambda_{\text {eff }}\right.$, Eq. (7)]. Assuming the total seismic moment is constant, for a range of the characteristic earthquake, the effective Poisson rate $\left(\lambda_{\text {eff }}\right)$ and a small $b_{c}$-value can be applied to a truncated exponential model. Figure 9 illustrates the earthquake recurrence comparison between the characteristic earthquake model and the truncated exponential model. For example, the fault source parameters include 200-year repeat time and characteristic magnitude range of 7.0 - 7.5. In the comparison, the result shows that the total seismic moment in the characteristic earthquake range for the truncated exponential model with a $b_{c}$-value of 0.2 is similar to the uniform distribution part of the characteristic earthquake model.

Therefore, a possible magnitude range of $\Delta_{M}=0.5$ for the characteristic earthquake is assumed for the hazard analysis (Fig. 3). To model the constant number for a fault using the truncated exponential model, the $b_{c}$-value is assumed to be as small as 0.2 to represent the nearly equal magnitude probability in the $f_{m c}(m)$. The characteristic earthquake fault recurrence, which causes the intensity to exceed the specific ground motion level $y$ at the study site in the time range of $\left[T_{e}, T_{e}+T_{p}\right]$, can be expressed as

$$
\lambda_{\text {fault }}=\sum_{j=1}^{N}\left\{\left[\int_{M_{C}-\Delta_{w} / 2}^{M_{C}+\Delta_{w} / 2} P\left(Y>y \mid E_{C, m}\right) f_{m C}(m) d m\right] \cdot \lambda_{e f f, C}\right\}_{C=j}
$$

where $E_{C, m}$ is the occurrence of a characteristic earthquake with magnitude $m$ in fault $C$, and $N$ is the number of faults in the study region.

In addition, the number of earthquakes that cause the same ground motion intensity as other time-independent earthquake sources are calculated using a constant rate per year on the basis of the Poisson process denoted as $\lambda$. The total number of earthquakes per year, $\lambda_{T}$, which cause the intensity to exceed the specific ground motion level $y$ at the study site in the consequent time period of $\left[T_{e}, T_{e}+T_{p}\right]$, be- comes $\lambda_{T}=\lambda_{\text {fault }}+\lambda$, in which $\lambda_{\text {fault }}$ means the effective Poisson rate per year from a summary of active faults according to any renewal model; $\lambda$ is the recurrence rate per year for the background seismicity modelled by the Poisson model.

\section{HAZARD CALCULATION OF FAULTS}

In the current Taiwan seismic building code the generated spectral value has 475 and 2475 year return periods, the traditional PSHA procedure with the constant rate of Poisson process model was used. In addition to the basic requirement for design, seismic design value of a site located near some identified specific faults also need to consider the near fault effect. Therefore, the important influence on the seismic design requirement during the structure lifetime will directly change according to the time-dependent earthquake model or the constant rate of Poisson process model.

For comparison, the time-dependent earthquake model and the constant rate of Poisson process model were applied for the following three faults in Taiwan: the Chelungpu, the Meishan and the Longitudinal Valley faults. It is important to point out that for the Meishan fault with the elapse time $\left(T_{e}\right)$ is almost equal to its recurrence interval $\left(T_{r}\right)$. The important influence on the hazard calculation using the timedependent model is more obviously presented than the Longitudinal Valley fault. The probability in the next $T_{p}$-year is certainly a distinct difference with the Chelungpu fault which last event happened in 1999.

In PSHA, the study site is located on the fault footwall surface distance equal to $2 \mathrm{~km}$ excluding the hang-wall effect and site effect. The earthquake source zone model adopts a conventional the seismic zoning scheme (Chang et al. 2010) for modelling the behaviour of the background seismicity (the catalogue of time from 1900 to June 2015). The rationale for using the zoning scheme is that it had been (and still is) used in a number of similar studies or projects in Taiwan, such as the Taiwan seismic building code. Five ground motion prediction equations (GMPEs) of NGA-West2 project (Bozorgnia et al. 2014) are adopted to evaluate the seismic risk in terms of strong ground motion (assume equal weighting in hazard calculation). The individual GMPEs include ASK (Abrahamson et al. 2014), BSSA (Boore et al. 2014), CB (Campbell and Bozorgnia 2014), CY (Chiou and Youngs 2014), and IM (Idriss 2014). The average shear-wave velocity in the top $30 \mathrm{~m}, V_{S 30}$, is $760 \mathrm{~m} \mathrm{~s}^{-1}$ in order to focus on the near fault effect in PSHA. This study neglects the site effect.

\subsection{Time-Dependent Probability}

Table 1 lists the characteristic parameters for the Chelungpu, Meishan and Longitudinal Valley faults, the times of the previous events $\left(T_{0}\right)$, and the earthquake fault recurrence intervals $\left(T_{r}\right)$. The occurrence probabilities for the 

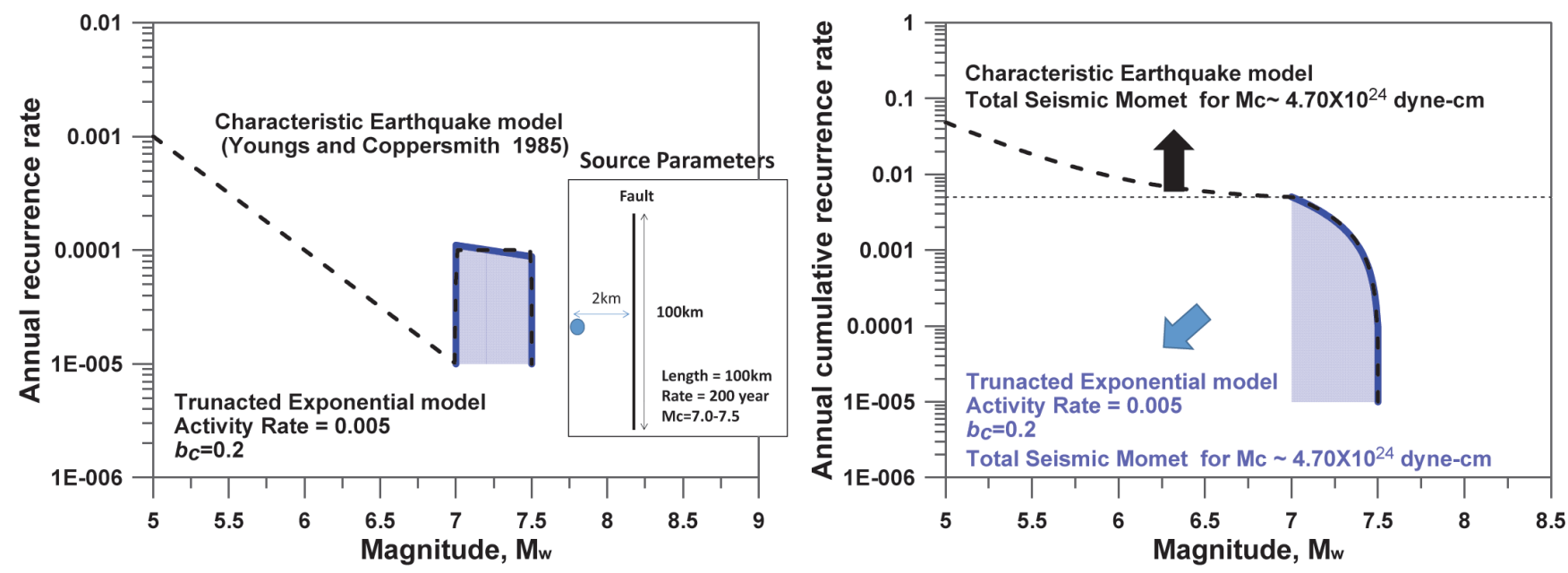

Fig. 9. Schematic illustration of the comparison of earthquake recurrence between the characteristic earthquake model and the truncated exponential model. The fault source parameters include that the repeat time is 200-year and the characteristic magnitude range is $7.0-7.5$. The $b_{c}$-value $=0.2$ is assumed in the truncated exponential model (blue area). The left is the recurrence rate of each magnitude; the right is the cumulative recurrence rate of each magnitude. (Color online only)

Table 1. The parameters for the renewal models of the Chelungpu, the Meishan and the Longitudinal Valley faults.

\begin{tabular}{c|c|c|c|c|c|c|c}
\hline Fault Name & geometry [Length $(\mathbf{k m}) /$ faulting / dip] & $\boldsymbol{T}_{\mathbf{0}}$ (Last EQ. time) & $\boldsymbol{T}_{e}$ & $\boldsymbol{M}_{\boldsymbol{c}}\left(\boldsymbol{M}_{w}\right)$ & $\boldsymbol{T}_{\boldsymbol{r}}(\boldsymbol{R} . \boldsymbol{P}$. & $\boldsymbol{T}_{p} / \boldsymbol{T}_{\boldsymbol{r}}$ & $\boldsymbol{T}_{e} / \boldsymbol{T}_{\boldsymbol{r}}$ \\
\hline Chelungpu & $105 \mathrm{~km} /$ Revise $/ 40^{\circ} \mathrm{E}$ & 1999.8 & 16.67 & $7.15-7.65$ & 365 & 0.1370 & 0.046 \\
Meishan & $25 \mathrm{~km} /$ Strike Slip $/ 75^{\circ} \mathrm{S}$ & 1906.3 & 110.17 & $6.75-7.25$ & 115 & 0.4348 & 0.958 \\
Longitudinal Valley & $150 \mathrm{~km} /$ Revise $/ 30^{\circ} \mathrm{E}$ & 1951.9 & 64.52 & $6.85-7.35$ & 150 & 0.3333 & 0.430 \\
\hline
\end{tabular}

Note: $T_{e}=$ elapse time; $T_{r}=$ earthquake recurrence interval of the fault $; T_{p}=$ a subsequent time equal 50 years.

three faults during a subsequent $T_{p}=50$ years (structural lifetime) considering the elapsed time, using both the timeindependent and time-dependent models corresponding to the five distributions (as Fig. 6) with $\mathrm{COV}=0.35,0.5$, and 0.7 are illustrated in Fig. 10. The result indicates that the 50year conditional probabilities from the four renewal models for the Chelungpu, Meishan, and Longitudinal Valley faults show a similar tendency. The conditional probability is proportional to the ratio between the elapsed time and the fault recurrence interval $\left(T_{e} / T_{r}\right.$ ratio). Weibull model adoption leads to a higher result than the others when the $T_{e} / T_{r}$ ratio is smaller as well as the $T_{e} / T_{r}$ ratio larger than 1 , as shown in Fig. 11. Figure 11 is the comparison of the five probability models used in estimated with Eq. (6) the next 50-year conditional probabilities of earthquake occurrence for example. All models have mean $=100$-year and COV $=0.5$ and 0.7 Because of the smaller $T_{e} / T_{r}$ ratio, the probability of $T_{p}=$ 50-year for the Chelungpu fault is highest from the Weibull model. It agrees with the Weibull hazard rate function that it starts at zero, however it does not reach a finite asymptotic level but rather increases to infinity as shown in Fig. 6b. The conditional probability estimation interrelates with the cumulative distribution shape of the renewal model. The shape is decided by COV. The conditional probability of renewal model conforms to the Poisson model when COV is large. Therefore, considering the 50-year conditional probability, the effective Poisson rate can be calculated using Eq. (7), as listed in Table 2, and is applied to the hazard calculation.

\subsection{Hazard Comparison}

In order to identify the time-dependent and time-independent model contributions used in PSHA, the hazard curves for the Chelungpu, Meishan and Longitudinal Valley faults using the Poisson and the BPT models are compared in Fig. 12. The justification is that although the most commonly used distribution in engineering practice is the Lognormal distribution, the statistic characteristic is restricted. It is discussed in section 5.1. The result shows that the hazard contribution for using both the time-dependent earthquake model and the constant-rate Poisson process model is significantly different. In this comparison, the effective Poisson rate, $\lambda_{\text {eff }}$, from Table 2 during a subsequent $T_{p}=50$ years is used for hazard calculation. For the Chelungpu fault (Fig. 12a), the constant rate model tends to overestimate the hazard near the fault site when $T_{e} / T_{r}$ ratio is smaller. This result implies that the seismic requirement in the return pe$\operatorname{riod}=475$ years since this site is overestimated about $25 \%$ 


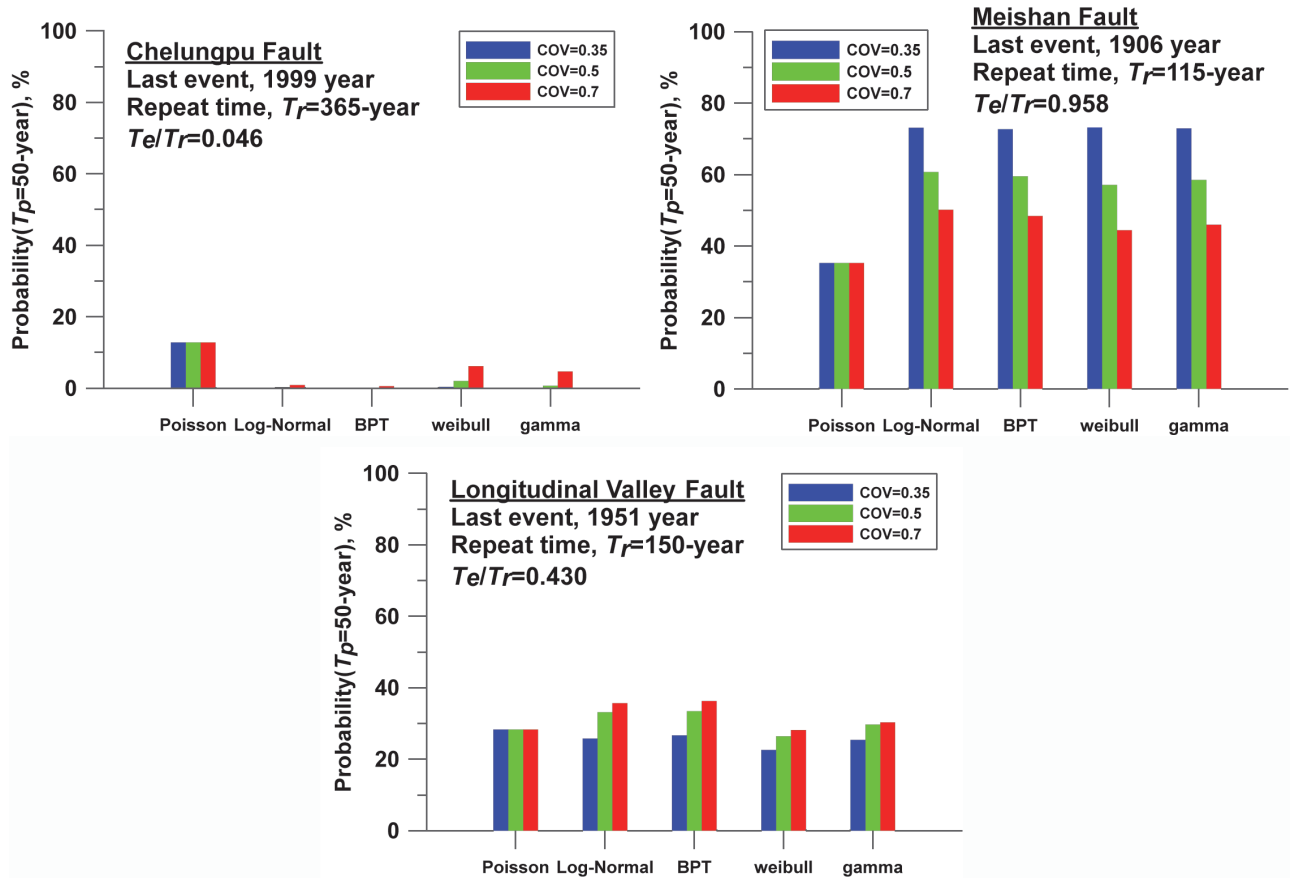

Fig. 10. The next 50-year conditional probabilities for earthquake occurrence for the Chelungpu, Meishan and Longitudinal Valley faults. A mean 365-year recurrence time is assumed for the Chelungpu fault, a mean 115-year recurrence time for the Meishan fault, and a mean 150-year recurrence time for the Longitudinal Valley fault. Graphs show the results using five distributions with COV $=0.35,0.5$, and 0.7 . (Color online only)
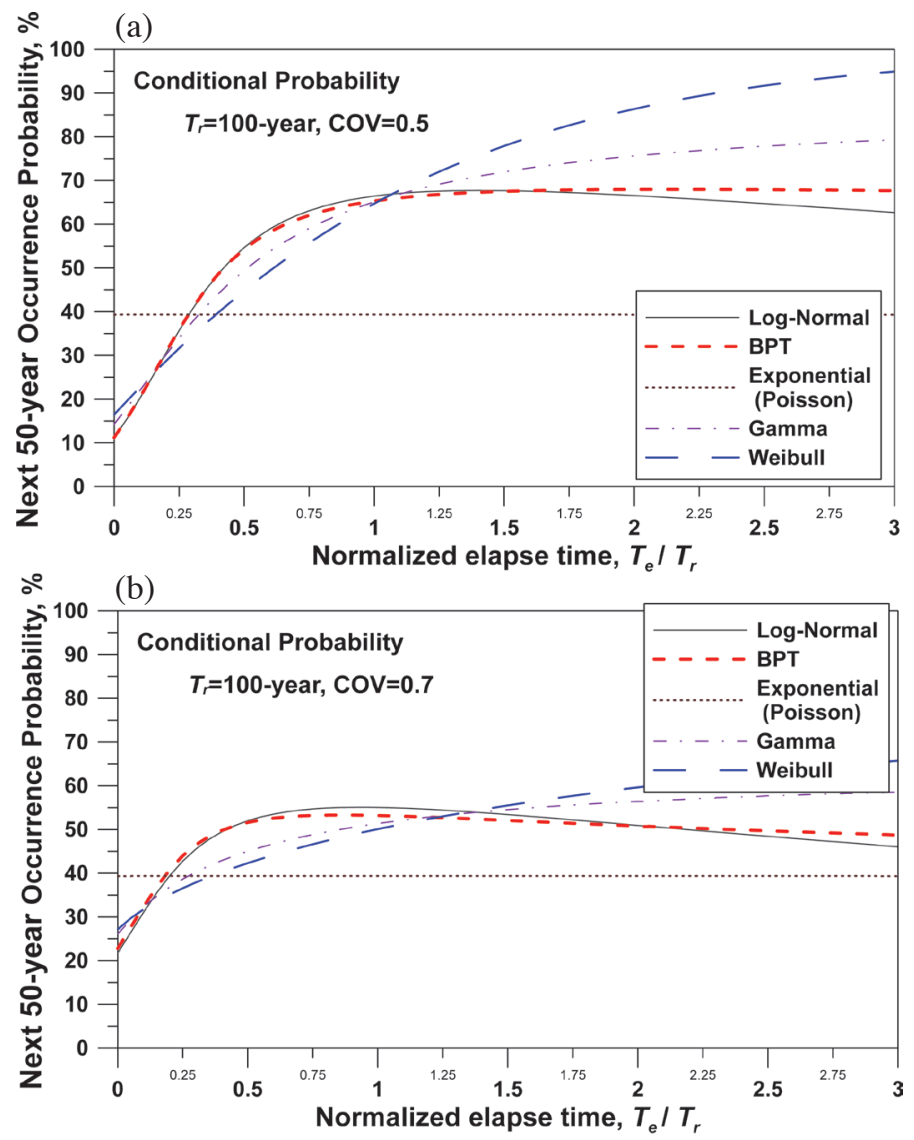

Fig. 11. Comparison of the five probability models used in estimated the next 50-year $\left(T_{p}\right)$ conditional probabilities of earthquake occurrence for example. All models have mean $=100$ years and $\mathrm{COV}=0.5$ for (a) and 0.7 for (b). (Color online only) 
Table 2. The effective Poisson rate $\left(T_{p}=50\right.$ years) by the renewal models using different COV for the Chelungpu, the Meishan and the Longitudinal Valley faults.

\begin{tabular}{c|c|ccccc}
\hline \multirow{2}{*}{ Fault Name } & \multirow{2}{*}{ COV } & \multicolumn{5}{c}{ Effective Poisson Rate $\left(\boldsymbol{T}_{p}=\mathbf{5 0}\right.$ years $)$} \\
\cline { 3 - 7 } & & Poisson & Log-normal & BPT & Weibull & Gamma \\
\hline \multirow{3}{*}{ Chelungpu } & 0.35 & 0.00274 & 0.00000 & 0.00000 & 0.00008 & 0.00000 \\
& 0.50 & 0.00274 & 0.00001 & 0.00000 & 0.00041 & 0.00013 \\
& 0.70 & 0.00274 & 0.00018 & 0.00011 & 0.00127 & 0.00096 \\
\hline \multirow{3}{*}{ Meishan } & 0.35 & 0.00870 & 0.02626 & 0.02595 & 0.02676 & 0.02613 \\
& 0.50 & 0.00870 & 0.01867 & 0.01809 & 0.01692 & 0.01759 \\
& 0.70 & 0.00870 & 0.01393 & 0.01323 & 0.01175 & 0.01230 \\
\hline \multirow{3}{*}{ Longitudinal Valley } & 0.35 & 0.00667 & 0.00596 & 0.00620 & 0.00512 & 0.00586 \\
& 0.50 & 0.00667 & 0.00805 & 0.00814 & 0.00614 & 0.00705 \\
& 0.70 & 0.00667 & 0.00882 & 0.00901 & 0.00662 & 0.00722 \\
\hline
\end{tabular}
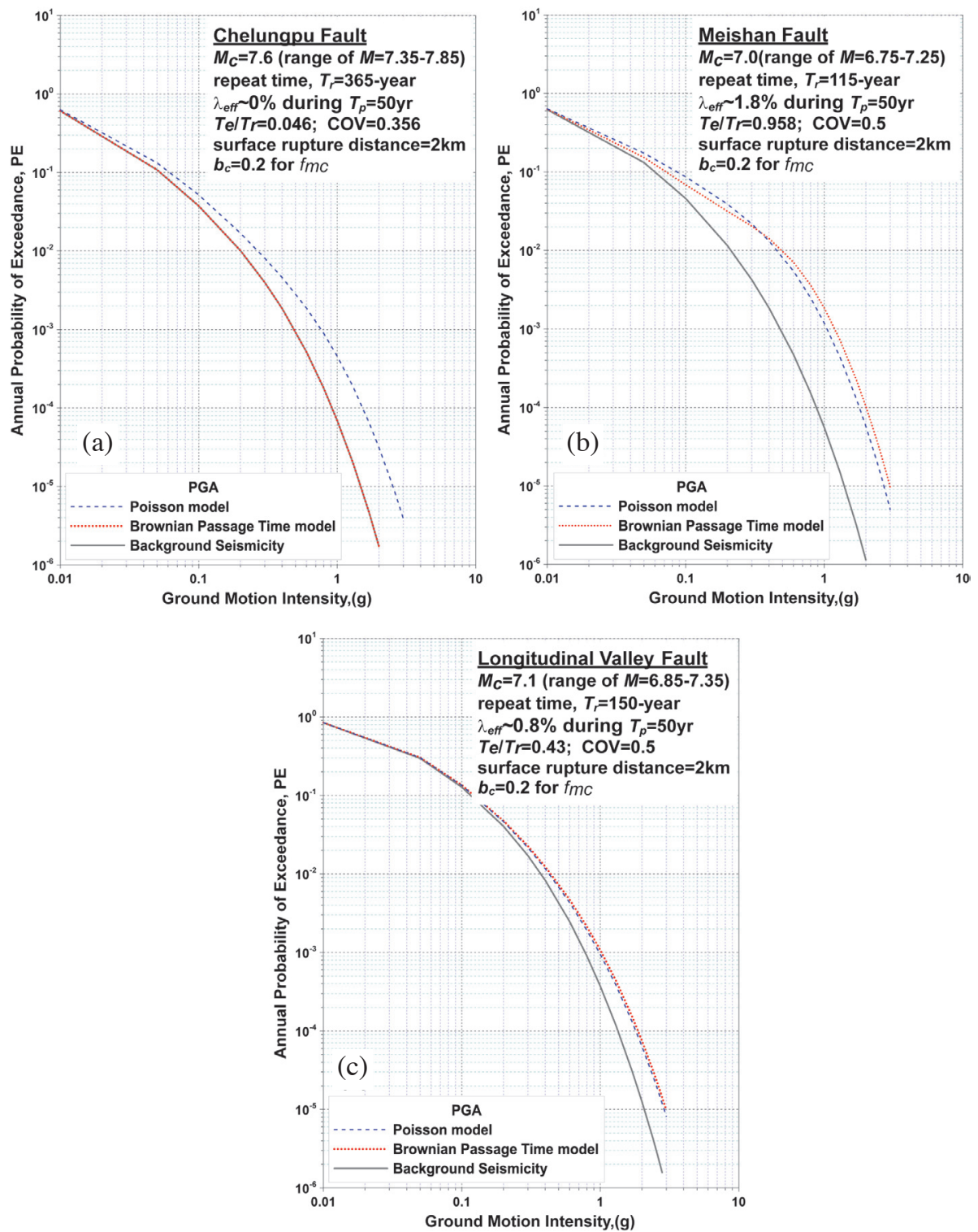

Fig. 12. Comparison of the PGA hazard curves using the time-independent and time-dependent models for the Chelungpu (a), the Meishan (b), and the Longitudinal Valley (c) faults. The study site is located on the footwall of the fault. Five NGA-West 2 GMPEs are used and assumed the $V_{S 30}=$ $760 \mathrm{~m} \mathrm{~s}^{-1}$. (Color online only) 
in the current Taiwan seismic building code (based on the Poisson model). Another case study is performed for a site near the Meishan fault, as shown in Fig. 12b, with an elapsed time $T_{e}$ almost equal to its mean recurrence interval. The large $T_{e} / T_{r}$ ratio for both hazard curves derived using either the time-independent model or time-dependent model is approximated to have the same hazard level. Figure 12c shows the constant rate model is similar to the time-dependent model because the $T_{e} / T_{r}$ ratio is close to 0.5 , such as the Longitudinal Valley fault.

\section{DISCUSSIONS}

\subsection{Sensitivity Analysis with Respect to the Renewal Model COV}

Reliable seismic hazard curve estimation via the PSHA approach requires considering uncertainties due to variables in the size, location and magnitude prediction for future earthquake events. In faults with low activity rates it is not easy to apply paleoseismological studies, therefore creating large uncertainties (Atakan et al. 2000). Both the Chelungpu and Longitudinal Valley faults provided sufficient fault-crossing trenching to constrain the history of past events. It is important to properly consider the variability in recurrence rates caused by multiple-segment ruptures that may change from event to event due to fault interaction. The variability in the recurrence interval can be referred to other faults in Taiwan, such as the Meishan fault, in which only one repeat time data can be identified from the historical earthquakes.

The conspicuous difference in the occurrence probability for time-predictable characteristic earthquakes in the next $T_{p}$-year subjected to the conditional constraint are from case studies on the Chelungpu and Meishan faults, which have existing different elapsed periods $T_{e}$. Figure 13 shows the 50-year occurrence probability of the four timedependent earthquake models using the Log-normal, BPT, Weibull and Gamma distributions with respect to $T_{e} / T_{r}$ ratio of COV values of $0.35,0.5$ and 0.7 , as well as for the Poisson probability.

The probability of occurrence increases or decreases with increasing COV values that have a $T_{e} / T_{r}$ ratio of approximately 0.3 and 0.6 of the Chelungpu and the Meishan faults, respectively. Oppositely, Fig. 13 shows that the renewal model leads to increasing probabilities with decreasing COV values when the $T_{e} / T_{r}$ ratio is greater than the intersection point. The decreasing results of the conditional probabilities using different renewal models consist with the varying COV values as shown in Fig. 10. It is concluded that as far as time dependence is concerned, the sensitivity of occurrence probability depends on the choice of the earthquake recurrence model and its corresponding COV.

In addition, Fig. 13a also shows the Log-normal distribution when applied to the renewal model. As the $T_{e} / T_{r}$ ratio is higher than 2.0 , the conditional probability begins to decrease, contrary to the basic renewal model concept that the probability goes up as the time since the last earthquake increases. Figure $13 \mathrm{~b}$ shows that the BPT model is very similar to the Log-normal model, but does not have the undesirable feature or decreasing probabilities for long recurrence times. For this reason, the BPT model is preferred over the Log-normal model. Figures $13 \mathrm{c}$ and d show that the Weibull and Gamma models are similar. However, the probability tendency of the Weibull model relates to its Hazard function that it does not reach a finite asymptotic level but rather increases to infinity.

\subsection{Sensitivity Analysis of $b_{c}$-value for the Characteristic Model}

The probability of the occurrence of individual faults estimated using the renewal model was used with consideration of the general form of the truncated exponential model, $f_{m c}(m)$, for characteristic earthquakes. In the hazard calculation for this study, the simple "characteristic earthquake model" is assumed using the truncated exponential model with the characteristic earthquake parameters, $M_{c}$, its range, recurrence rate, and $b_{c}$-value. The characteristic earthquake, $M_{c}$, is the centre of the magnitude range. The recurrence rate relates to the effective Poisson rate per year of conditional probability for the next $T_{p}$-year. The schematic illustration of the cumulative probability density function of magnitude is shown in Fig. 9. Figure 14 illustrates a comparison of the hazard curves using different $b_{c}$-value in the truncated exponential model. For the Meishan fault, the characteristic earthquake range is $6.75-7.25\left(M_{c}=7.0\right)$ to coordinate with the $\lambda_{\text {eff }}$ equal to $0.018 \mathrm{yr}^{-1}$ (related to Table 2). The models include an exponential distribution with the $b_{c}$-value for the large magnitude earthquakes and an exponential distribution with the $b$-value equal to 1.0 for the smaller magnitude earthquakes. An additional constraint is done by following the Youngs and Coppersmith (1985) characteristic model setting. The comparison result shows that reducing the $b_{c}$ value in the exponential distribution increases in the hazard contributions of a large earthquake. This study highlights that the characteristic behavior of a fault is described by the truncated exponential model within a characteristic magnitude range in which the change in $b_{c}$-value produces a very small difference in hazard. It is a fact that a fault could be in equilibrium by releasing the seismic moment of long-term accumulation in characteristic earthquakes. The Characteristic Earthquake Model by Youngs and Coppersmith (1985) assumes a uniform distribution with the fault slip-rate of the large earthquakes, and the total seismic moment being released in larger size earthquakes and smaller earthquakes. The truncated exponential model using a low $b_{c}$-value is similar to the uniform distribution for a range of large earthquakes. It assumes that all of the seismic energy is released 

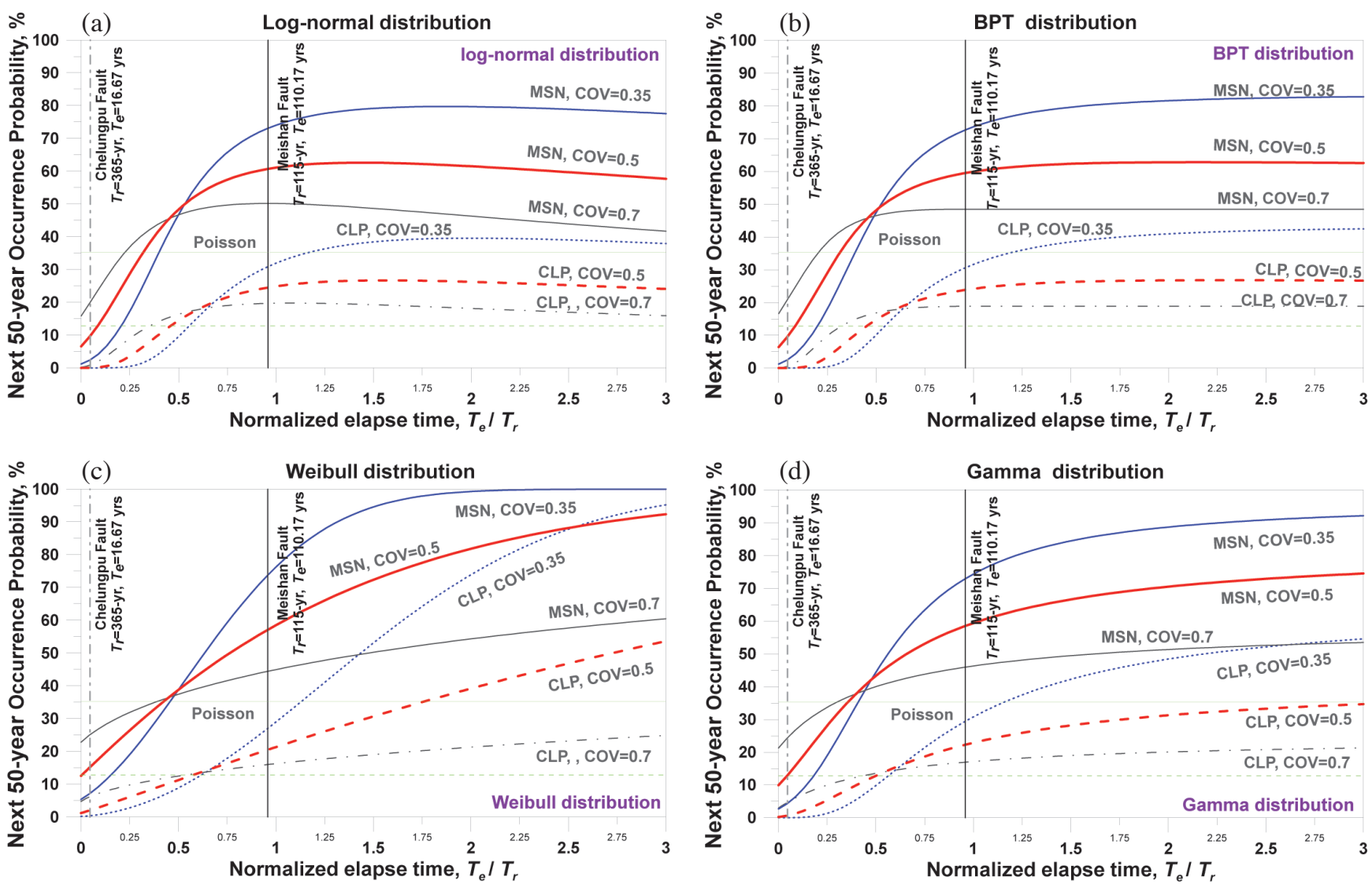

Fig. 13. Comparison of the next 50-year conditional probabilities of the individual faults characterized by the four dependent models [(a) Lognormal, (b) BPT, (c) Weibull, (d) Gamma] and Poisson model, calculated from COV value of 0.3, 0.5 and 0.7, respectively. (Color online only)

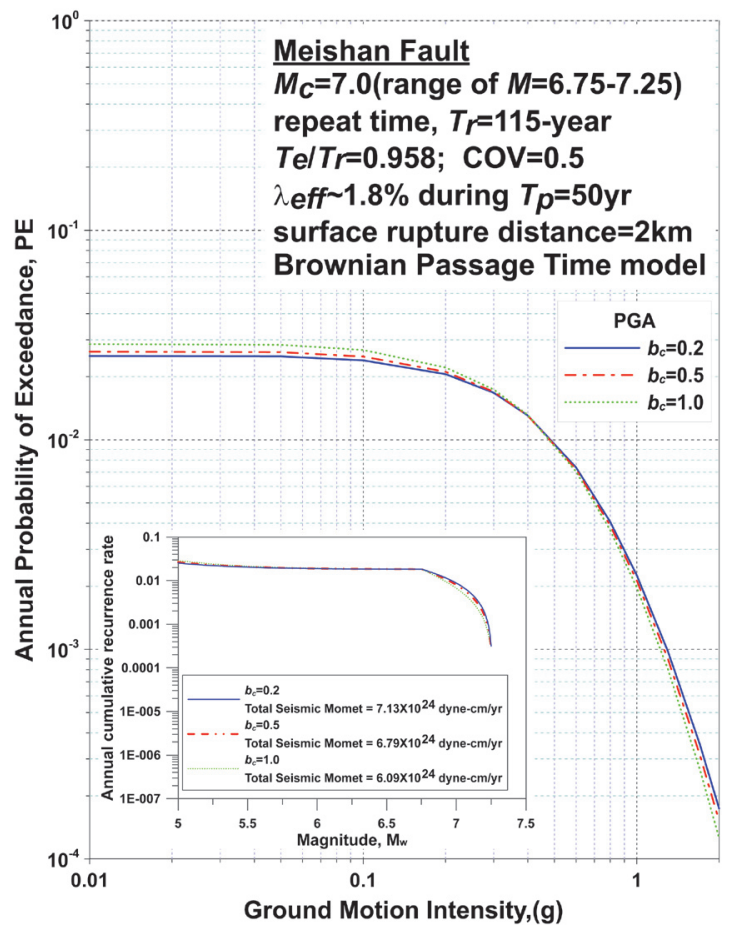

Fig. 14. Comparison of the PGA hazard curves for a site near the Meishan fault between considering different $b_{c}$-value in the truncated exponential model, $f_{m c}(\mathrm{~m})$, for the characteristic earthquake range. The cumulative probability density function of magnitude for describing the relative rate of earthquakes are compared. (Color online only) 
in a range of characteristic earthquakes. The cumulative probability density function of magnitude for describing the relative rate of earthquakes are compared in Fig. 14. It indicates that the truncated exponential model with different $b_{c}$-value calculate a similar total seismic moment, related to the very small difference in hazard calculation.

\section{CONCLUSION}

Giving the probability distribution function of recurrence interval and the occurrence time for the most recent characteristic earthquake event on a fault, a time-dependent assessment of seismic hazard is developed in this study that takes into account the cyclic rupture characteristics of active faults for a particular lifetime.

In the case of faults that recently occurred, or $T_{e}$ is short, the constant occurrence rate model may overestimate the seismic hazard for a given specific ground motion level. Accordingly, the constant occurrence rate model (uniform Poisson process model) may underestimate the seismic hazard for the case of faults that have not occurred for a long time. With this view point, the seismic requirement is lower than those for the current design code for the area along the Chelungpu fault, but is opposite when a site is located near the Meishan fault. The percentage of the difference on seismic hazard demand between the Poisson model and timedependent model will have about $25 \%$ difference on the site located near the Chelungpu fault. To reflect the real physical phenomenon it is necessary to consider the time-dependent earthquake recurrence frequency model in the hazard calculation. The result can provide a reference to compare the current seismic design code for the seismic design at the specific site near a fault.

The recurrence time for a fault estimated from paleoearthquakes studies can only estimate a period for historic earthquake occurrences, but not the exact time. Therefore, it is necessary to consider the randomness of the occurrence intervals for large earthquakes. Furthermore, the occurrence probability sensitive analysis for $\mathrm{COV}$ indicates that the occurrence probability depends on different $\mathrm{COV}$ values used in the renewal model. The results show that the hazard calculation based on the constant occurrence rate may not lead to adequate results, especially on sites near a fault.

Considering the uncertainty of the fault recurrence interval, the slip rate will be one of the parameters used to estimate the range of the uncertainty. The slip rate of an individual fault was developed by Shyu et al. (2016) based on the seismogenic structural data in Taiwan. In future studies, combining the slip rate with the occurrence time of the last event, a time-dependent model will be able to be developed for each fault in Taiwan. The conditional probability estimation effect using the fault recurrence interval estimated using historic earthquakes and slip rates needs further study. More sensitivity analysis for the conditional probabilities using different renewal models also needs to be studied.

Acknowledgements The study was supported by the National Center for Research on Earthquake Engineering (NCREE, Taiwan) and Ministry of Science \& Technology under grant No. MOST 104-2625-M-002-016.

\section{REFERENCES}

Abrahamson, N. A., W. J. Silva, and R. Kamai, 2014: Summary of the ASK14 Ground Motion Relation for Active Crustal Regions. Earthq. Spectra, 30, 1025-1055, doi: 10.1193/070913EQS198M. [Link]

Akinci A., D. Perkins, A. M. Lombardi, and R. Basili, 2010: Uncertainties in probability of occurrence of strong earthquakes for fault sources in the Central Apennines, Italy. J. Seismol., 14, 95-117, doi: 10.1007/s10950008-9142-y. [Link]

Atakan, K., V. Midzi, B. M. Toiran, K. Vanneste, T. Camelbeeck, and M. Meghraoui, 2000: Seismic hazard in regions of present day low seismic activity: uncertainties in the paleoseismic investigations along the Bree Fault Scarp (Roer Graben, Belgium). Soil Dyn. Earthq. Eng ., 20, 415-427, doi: 10.1016/s0267-7261(00)00081-6. [Link]

Boore, D. M., J. P. Stewart, E. Seyhan, and G. M. Atkinson, 2014: NGA-West2 Equations for Predicting PGA, PGV, and 5\% Damped PSA for Shallow Crustal Earthquakes. Earthq. Spectra, 30, 1057-1085, doi: 10.1193/070113EQS184M. [Link]

Bozorgnia Y., N. A. Abrahamson, L. A. Atik, T. D. Ancheta, G. M. Atkinson, J. W. Baker, A. Baltay, D. M. Boore, K. W. Campbell, B. S. J. Chiou, R. Darragh, S. Day, J. Donahue, R. W. Graves, N. Gregor, T. Hanks, I. M. Idriss, R. Kamai, T. Kishida, A. Kottke, S. A. Mahin, S. Rezaeian, B. Rowshandel, E. Seyhan, S. Shahi, T. Shantz, W. Silva, P. Spudich, J. P. Stewart, J. Watson-Lamprey, K. Wooddell, and R. Youngs, 2014: NGA-West2 research project. Earthq. Spectra, 30, 973-987, doi: 10.1193/072113EQS209M. [Link]

Campbell, K. W. and Y. Bozorgnia, 2014: NGA-West2 ground motion model for the average horizontal components of PGA, PGV, and 5\% damped linear acceleration response spectra. Earthq. Spectra, 30, 1087-1115, doi: 10.1193/062913EQS175M. [Link]

Chang, Y. W., W. Y. Jean, C. H. Loh, and K. L. Wen, 2007: The application of time-predictable characteristic earthquake model for evaluation of design earthquake in Taiwan. 10 ${ }^{\text {th }}$ International Conference on Applications of Statistics and Probability in Civil Engineering, Japan, No.72 CD-ROM.

Chang, Y. W., W. Y. Jean, and S. B. Chiou, 2010: Study on Design Earthquakes for Kinmen, Matsu and Penhu Areas. Report of National Center for Research on 
Earthquake Engineering, NARL, No. NCREE-10-016, 76 pp. (in Chinese)

Chiou, B. S. J. and R. R. Youngs, 2014: Update of the Chiou and Youngs NGA Model for the Average Horizontal Component of Peak Ground Motion and Response Spectra. Earthq. Spectra, 30, 1117-1153, doi: 10.1193/072813EQS219M. [Link]

Chen, W. S., Y. G. Chen, T. K. Liu, N. W. Huang, C. C. Lin, S. H. Sung, and K. J. Lee, 2000: Characteristics of the Chi-Chi earthquake ruptures. Central Geol. Surv. Spec. Publ., 12, 139-154.

Chen, W. S., K. J. Lee, L. S. Lee, D. J. Ponti, C. Prentice, Y G. Chen, H. C. Chang, and Y. H. Lee, 2004: Paleoseismology of the Chelungpu fault during the past 1900 years. Quat. Int., 115-116, 167-176, doi: 10.1016/ s1040-6182(03)00105-8. [Link]

Chen, W. S., C. C. Yang, I. C. Yen, L. S. Lee, K. J. Lee, H. C. Yang, H. C. Chang, Y. Ota, C. W., Lin, W. H. Lin, T. S. Shih, and S. T. Lu, 2007: Late Holocene paleoseismicity of the southern part of the Chelungpu fault in central Taiwan: Evidence from the Chushan excavation site. Bull. Seismol. Soc. Am., 97, 1-13, doi: 10.1785/0120050161. [Link]

Cheng, S. N., Y. T. Yeh, M. T. Hsu, and T. C. Shin, 1999: Atlas of Ten Disastrous Earthquakes in Taiwan, Central Weather Bureau, Ministry of Transportation and Communication, 290 pp. (in Chinese)

Cornell, C. A, 1968: Engineering Seismic Risk Analysis. Bull. Seismol.Soc. Am., 58, 1583-1606.

Cornell, C. A. and S. R. Winterstein, 1988: Temporal and magnitude dependence in earthquake recurrence models. Bull. Seismol. Soc. Am., 78, 1522-1537, doi: 10.1007/978-3-642-83252-9_2. [Link]

Cramer, C. H., M. D. Petersen, T. Cao, T. R. Toppozada, and M. Reichle, 2000: A time-dependent probabilistic seismic hazard model for California. Bull. Seismol. Soc. Am., 90, 1-21, doi: 10.1785/0119980087. [Link]

Der Kiureghian, A. and A. H.-S. Ang, 1977: A fault-rupture model for seismic risk analysis. Bull. Seismol. Soc. Am., 67, 1173-1194.

Ellsworth, W. L., M. V. Matthews, R. M. Nadeau, S. P. Nishenko, P. A. Reasenberg, and R. W. Simpson, 1999: A Physically-Based Earthquake Recurrence Model for Estimation of Long-Term Earthquake Probabilities. U. S. Geological Survey Open-File Report, No. 99-522, U. S. Dept. Interior, 23 pp.

Field, E. H., G. P. Biasi, P. Bird, T. E. Dawson, K. R. Felzer, D. D. Jackson, K. M. Johnson, T. H. Jordan, C. Madden, A. J. Michael, K. R. Milner, M. T. Page, T. Parsons, P. M. Powers, B. E. Shaw, W. R. Thatcher, R. J. Weldon, and Y. Zeng, 2015: Long-Term time-dependent probabilities for the third uniform California earthquake rupture forecast (UCERF3). Bull. Seismol. Soc. Am., 105, 511-543, doi: 10.1785/0120140093.
[Link]

Fujiwara, H., S. Kawai, S. Aoi, and Y. Hayakawa, 2005: National Seismic Hazard Maps for Japan, Headquarters for Earthquake Research Promotion, Earthquake Research Committee, 162 pp.

Fujiwara, H., N. Morikawa, Y. Ishikawa, T. Okumura, J. Miyakoshi, N. Nojima, and Y. Fukushima, 2009: Statistical comparison of national probabilistic seismic hazard maps and frequency of recorded JMA seismic intensities from the K-NET strong-motion observation network in Japan during 1997-2006. Seismol. Res. Lett., 80, 458-464, doi: 10.1785/gssrl.80.3.458. [Link]

Garcia-Aristizabal A., W. Marzocchi, and E. Fujita, 2012: A Brownian model for recurrent volcanic eruptions: an application to Miyakejima volcano (Japan). Bull. Volcanol., 74, 545-558, doi: 10.1007/s00445-011-0542-4. [Link]

González, Á., J. B. Gómez, and A. F. Pacheco, 2006: Updating seismic hazard at Parkfield. J. Seismol., 10, 131135, doi: 10.1007/s10950-005-9005-8. [Link]

Gutenberg, B. and C. F. Richter, 1944: Frequency of earthquakes in California. Bull. Seismol. Soc. Am., 34, 185188.

Hanks, T. C. and H. Kanamori, 1979: A moment-magnitude scale. J. Geophys Res., 84, 2348-2350, doi: 10.1029/ JB084iB05p02348. [Link]

Hong, L. L. and S. W. Guo, 1995: Nonstationary Poisson Model for Earthquake Occurrences. Bull. Seismol. Soc. Am., 85, 814-824.

Idriss, I. M., 2014: An NGA-West2 empirical model for estimating the horizontal spectral values generated by Shallow Crustal Earthquakes. Earthq. Spectra, 30, 1155-1177, doi: 10.1193/070613EQS195M. [Link]

Jackson, D. D., K. Aki, C. Cornell, J. H. Dieterich, T. Henyey, M. Mahdyiar, D. Schwartz, and, S. N. Ward, 1995: Seismic hazards in Southern California: probable earthquake, 1994 to 2024. Bull. Seismol. Soc. Am., 85, 379-439.

Jean, W. Y., Y. W. Chang, C. H. Loh, and K. L. Wen, 2006: The probability seismic analysis and the scenario earthquake. Conferences Commemoration of 100th Anniversary of the 1906 Meishan Earthquake Taiwan. (in Chinese)

Matthews, M. V., W. L. Ellsworth, and P. A. Reasenberg, 2002: A Brownian model for recurrent earthquakes. Bull. Seismol. Soc. Am., 92, 2233- 2250, doi: 10.1785/0120010267. [Link]

McGuire, R. K., 1976: FORTRAN computer program for seismic risk analysis. Open-File Report, U. S. Geological Survey, 76-67.

McGuire, R. K., 1995: Probabilistic seismic hazard analysis and design earthquakes: Closing the loop. Bull. Seismol. Soc. Am., 85, 1275-1284.

McGuire, R. K., 2004: Seismic Hazard and Risk Analysis, 
Earthquake Engineering Research Institute, $221 \mathrm{pp.}$

Mosca I., R. Console, and G. D’Addezio, 2012: Renewal models of seismic recurrence applied to paleoseismological and historical observations. Tectonophysics, 564-565, 54-67, doi: 10.1016/j.tecto.2012.06.028. [Link]

Nishenko, S. P. and R. Buland, 1987: A generic recurrence interval distribution for earthquake forecasting. Bull. Seismol. Soc. Am., 77, 1382-1399.

Ogata, Y., 1999: Estimating the hazard of rupture using uncertain occurrence times of paleoearthquakes. J. Geophys. Res., 104, 17995-18014, doi: 10.1029/1999JB900115. [Link]

Parsons, T., 2005: Significance of stress transfer in timedependent earthquake probability calculations. J. Geophys. Res., 110, doi: 10.1029/2004JB003190. [Link]

Parsons, T., 2006: $M \geq 7.0$ earthquake recurrence on the San Andreas fault from a stress renewal model. J. Geophys. Res., 111, doi: 10.1029/2006JB004415. [Link]

Parsons, T. and E. L. Geist, 2009: Is there basis for preferring characteristic earthquakes over Gutenberg-Richter distributions on individual faults in probabilistic earthquake forecasting? Bull. Seismol. Soc. Am., 99, 20122019, doi: 10.1785/0120080069. [Link]

Schwartz, D. P. and K. J. Coppersmith, 1984: Fault behavior and characteristic earthquakes: Examples from the Wasatch and San Andreas Fault Zones. J. Geophys. Res., 89, 5681-5698, doi: 10.1029/JB089iB07p05681. [Link]

Shyu, J. B. H., Y. R. Chuang, Y. L. Chen, Y. R. Lee, and C. T. Cheng, 2016: A new on-land seismogenic structure source database from the Taiwan Earthquake Model (TEM) project for seismic hazard analysis of Taiwan. Terr. Atmos. Ocean. Sci., 27, 311-323, doi: 10.3319/ TAO.2015.11.27.02(TEM). [Link]
Sykes, L. R. and W. Menke, 2006: Repeat times of large earthquakes: Implications for earthquake mechanics and long-term prediction. Bull. Seismol. Soc. Am., 96, 1569-1596, doi: 10.1785/0120050083. [Link]

Wells, D. L. and K. J. Coppersmith, 1994: New empirical relationships among magnitude, rupture length, rupture width, rupture area, and surface displacement. Bull. Seismol. Soc. Am., 84, 974-1002.

Wesnousky, S. G., 1994: The Gutenburg Richter or Characteristic Earthquake Distribution, which is it? Bull. Seismol. Soc. Am., 84, 1940-1959.

Wesnousky, S. G. and C. H. Scholz, 1983: Earthquake frequency distribution and the mechanics of faulting. J. Geophys. Res., 88, 9331-9340, doi: 10.1029/ JB088iB11p09331. [Link]

Working Group on California Earthquake Probabilities (WGCEP), 2003: Earthquake Probabilities in the San Francisco Bay Region: 2002-2031. Open-File Report, U.S. Geological Survey, No. 03-214, 234 pp.

Working Group on California Earthquake Probabilities (WGCEP), 2007: The Uniform California earthquake rupture forecast, version 2 (UCERF x2). Open-File Report, U.S. Geological Survey, No. 07-1437.

Yen, I. C., W. S. Chen, C. C. B. Yang, N. W. Huang, and C. W. Lin, 2008: Paleoseismology of the Rueisuei Segment of the Longitudinal Valley Fault, Eastern Taiwan. Bull. Seismol. Soc. Am., 98, 1737-1749, doi: 10.1785/0120070113. [Link]

Youngs, R. R. and K. J. Coppersmith, 1985: Implications of fault slip rates and earthquake recurrence models to probabilistic seismic hazard estimates. Bull. Seismol. Soc. Am., 75, 939-964.

Yu, S. B., H. Y. Chen, and L. C. Kuo, 1997: Velocity field of GPS stations in the Taiwan area. Tectonophysis, 274, 41-59, doi: 10.1016/S0040-1951(96)00297-1. [Link] 